\title{
EFFECT OF EMBLICA OFFICINALIS FRUIT DRY POWER ON BEHAVIOR CHANGES AND ANTIOXIDANT LEVELS: AN IN VITRO AND IN VIVO STUDY
}

\author{
UMAMAHESWARI A*, BHUVANESWARI K, MUTHURAMAN PL
}

Department of Pharmacology, PSG Institute of Medical Sciences and Research, The Tamil Nadu Dr. MGR Medical University, Coimbatore, Tamil Nadu, India. Email: dr.uma.pharmac@gmail.com

Received: 15 April 2019, Revised and Accepted: 30 May 2019

\section{ABSTRACT}

Objective: This study aim was to compare the in vitro antioxidant property of fresh juice and dry powder of Emblica officinalis (E0) by chemical testing and 2,2-diphenyl-1-picryl-hydrazyl-hydrate (DPPH) assay and also to observe the in vivo effect of EO fruit dry powder on food intake, body weight, behavior changes, and antioxidant levels in restraint stress rat model.

Methods: In vitro study, EO fresh juice $1 \% \mathrm{v} / \mathrm{v}$ and its dry powder form were analyzed for chemical testing and DPPH assay initially. In the in vivo study, 12 adult male Wistar rats were obtained. Initially, baseline parameters (Body wt, food intake, behavior changes, blood levels of superoxide dismutase, and malondialdehyde) and control values were assessed. Later 12 animals were divided into two treatment groups (1 and 2) and pretreatment was given with dry powder of EO at a dose of $250 \mathrm{mg} / \mathrm{kg}$ and $500 \mathrm{mg} / \mathrm{kg}$ orally once a day, respectively. Animals from both the groups were restrained for $2 \mathrm{~h} /$ day and the same parameters were analyzed at the end of $24 \mathrm{~h}$ and 7 days of stress induction.

Results: In vitro study, fresh juice and dry powder preparations of EO were found to be positive for all the four chemical testing. In DPPH assay, dry powder showed better antioxidant activity (97\%) than the fresh juice form (57\%). In vivo study, significant antioxidant activity was seen at the dose of $500 \mathrm{mg} / \mathrm{kg}$ after day 1 and 7 days of stress induction.

Conclusion: Dry powder of EO has brought out the reversal of restraint stress-induced behavioral changes and reduced food intake, body weight, and antioxidant levels.

Keywords: Antioxidant property, 2,2-diphenyl-1-picryl-hydrazyl-hydrate assay, Emblica officinalis, Restraint stress, Rats.

(C) 2019 The Authors. Published by Innovare Academic Sciences Pvt Ltd. This is an open access article under the CC BY license (http://creativecommons. org/licenses/by/4. 0/) DOI: http://dx.doi.org/10.22159/ajpcr.2019.v12i7.33619

\section{INRODUCTION}

Oxidative stress is the result of an imbalance between oxidants and antioxidants. Physical or psychological stress induces a change in the hypothalamic-pituitary-adrenal axis which releases glucocorticoids and chemical mediators including adrenocorticotropic hormone, norepinephrine, serotonin, dopamine, and acetylcholine. The metabolism of these mediators leads to more production of free radicals and reactive oxygen species (ROS), which later causes an imbalance between oxidants and antioxidants. Acute stress in any organism will produce compensatory responses to restore previous stability. However, in chronic stress, ROS put forth negative effects and becomes a major causative factor implicated in several pathologies - cardiovascular, immunological, neurodegenerative, or neuro behavior changes [1]. Antioxidant enzymes such as superoxide dismutase (SOD), catalase, and glutathione peroxidase play important roles in scavenging free radicals and preventing cell injury. When the mechanism of antioxidant protection becomes unbalanced in the human body, an antioxidant supplement may be used to help reduce oxidative damage [2]. Synthetic antioxidants are commercially available. By considering potential health risks and toxicity of synthetic antioxidants (butylhydroxytoluene and butylhydroxyanisole), researchers have drawn their attention toward the natural occurring antioxidants (plant materials) $[3,4]$.

Studies have demonstrated that plant phenolics as a major source of natural antioxidants. The fruit of Indian Gooseberry (Emblica officinalis [EO]) is rich in Vitamin $\mathrm{C}$ and it acquires maximum antibacterial and antioxidative activities [5]. The unique antioxidants such as Gallic acid, Vitamin C, ß-carotene, and SOD enzyme have been reported to be present in the fruit. Various studies have shown the antioxidant property of EO in various forms of its extractions (ethanol and methanol) [5,6].
Stress is well known to change body weight and food intake in animal models. Many studies have shown that restraint stress suppresses body weight gain and food intake in rodents [7]. No studies have explored the in vivo effects of EO fruit dry powder on a combination of food intake, body weight, behavior changes, and antioxidant levels in a whole animal model. Hence, the study was designed to compare the in vitro antioxidant property of fresh juice and dry powder preparations of EO by chemical testing and 2,2-diphenyl-1-picryl-hydrazyl-hydrate (DPPH) assay and also to observe the in vivo effect of EO fruit dry powder on food intake, body weight, general behavior changes, and antioxidant levels (SOD), malondialdehyde (MDA) in an adult male Wistar rat model after restraint stress induction.

\section{MATERIALS AND METHODS}

Fresh fruits of EO were obtained from the local market and washed thoroughly in running water. Under sterile condition, the fruits were cut into pieces and seeds were removed and weighed. Then dried in a hot air oven at $60^{\circ} \mathrm{C}$ aseptically and grinded to get a fine powder form. EO fresh juice $1 \% \mathrm{v} / \mathrm{v}$ was prepared. Both the preparations were used for DPPH assay and chemical testing.

\section{Chemical testing}

Detection of phenolic compounds

- Ferric chloride test: Juice and the dry powder forms of EO were added to $5 \% \mathrm{FeCl}_{3}$ reagent and the formation of deep blue color was observed

- Lead acetate test: Juice and the dry powder forms of EO were added to $10 \%$ lead acetate solution and mixed. Formation of white precipitate was observed [8]. 


\section{Detection of flavonoids}

Aqueous sodium hydroxide test: Juice and the dry powder forms of EO were treated along with aqueous $\mathrm{NaOH}$ solution. Formation of yelloworange color was observed.

$\mathrm{H}_{2} \mathrm{SO}_{4}$ test: Juice and the dry powder forms of EO were added to concentrate $\mathrm{H}_{2} \mathrm{SO}_{4}$ and observed for the formation of the orange color [8].

\section{DPPH assay}

The dry powder and fresh juice of EO were prepared in $1 \% \mathrm{w} / \mathrm{v}$ and $1 \% \mathrm{v} / \mathrm{v}$ solutions, respectively. The samples were reacted with the stable DPPH radical in an ethanol solution. The reaction mixture consisted of adding $0.5 \mathrm{~mL}$ of samples (dry powder and Fresh juice), $3 \mathrm{~mL}$ of absolute ethanol and $0.3 \mathrm{~mL}$ of DPPH radical solution $0.5 \mathrm{mM}$ in ethanol. When DPPH reacted with an antioxidant compound, which donated hydrogen and it was reduced. The change in color (from deep violet to light yellow) was read (Absorbance [Abs]) at $517 \mathrm{~nm}$ after $100 \mathrm{~min}$ of reaction using an ultraviolet-visible spectroscopy spectrophotometer. The mixture of ethanol $(3.3 \mathrm{~mL})$ and sample $(0.5 \mathrm{~mL})$ served as blank. The control solution was prepared by mixing ethanol $(3.5 \mathrm{~mL})$ and DPPH radical solution ( $0.3 \mathrm{~mL})$. Reference standard compound being used was ascorbic acid $50 \mathrm{ng} / \mathrm{ml}$. Lower Abs of the reaction mixture indicated higher free radical activity [9-12]. Percentage inhibition was calculated by.

DPPH scavenging effect $(\%)=\mathrm{A} 0-\mathrm{A} 1 / \mathrm{A} 0 \times 100$.

Where A0 was the Abs of control reaction and A1 was the Abs in the presence of test or standard sample (control $=0.856$ ).

In vivo

After getting approval from the Institutional Animal Ethics Committee, 12 adult male Wistar rats weighing 150-250 g were obtained and divided into two groups of six each. Initially, six animals were assessed for the baseline values of the parameters (body weight, food intake, behavior changes, blood levels of SOD, and MDA) and then those six animals were used as control (without treatment) and subjected to psychological stress by restraining for $2 \mathrm{~h}$ and the above said parameters were assessed at the end of $24 \mathrm{~h}$ and after 7 days of stress induction. This method was aimed toward reducing animal usage in the study. Then, 2 weeks interval period was allowed to acclimatize the animals back to its normal laboratory environment and to overcome the stress induction. Later then, total of 12 animals were randomly divided into two treatment groups. For Groups 1 and 2, pre-treatment with EO dry powder at a dose of $250 \mathrm{mg} / \mathrm{kg}$ body weight and $500 \mathrm{mg} / \mathrm{kg}$ body weight orally $[13,14]$ was given once daily. Pre-treated animals from both groups were restrained for $2 \mathrm{~h} /$ day, and the same tests were repeated at the end of $24 \mathrm{~h}$ and after 7 days of stress induction. The body weight of the animals was measured in each group at the end of $24 \mathrm{~h}$ and after 7 days. Food intake in grams was measured for each animal in both groups at the end of $24 \mathrm{~h}$ and after 7 days using Oxylet system. Food intake in dark/light phase cycle was measured and compared with controls.

\section{Behavior changes}

Open field test: locomotor activity (quiet room)

On the day of testing, rats were allowed to adapt to the environment for $1 \mathrm{~h}$ before testing. After $5 \mathrm{~min}$ of acclimatization in the open field apparatus, each animal from the respective treatment group was placed individually in the center of the open field and number of squares crossed, number of rearings (number of times the animal stood on its hind legs), grooming (duration of time the animal spent licking or scratching itself while stationary), and fecal pellets were observed for a period of $5 \mathrm{~min}$ [15].

\section{SOD and MDA levels}

End of $24 \mathrm{~h}$ and on the $8^{\text {th }}$ day, $1 \mathrm{ml}$ of blood was withdrawn from rat tail vein for the analysis of SOD and MDA levels.

\section{Estimation of $S O D$}

Reagents used were Tris buffer - $50 \mathrm{ml}$ (containing $50 \mathrm{mM}$ of Tris and $1 \mathrm{mM}$ of ethylenediaminetetraacetic acid), hydrochloric acid - adjust $\mathrm{PH}$ at 8.5 , and Pyrogallol $-25 \mathrm{mg}$ added to $10 \mathrm{ml}$ of distilled H2O (20 mM conc.). For blank: $2.9 \mathrm{ml}$ Tris $+0.1 \mathrm{ml}$ Pyrogallol- Mixed well. Abs A was read at $420 \mathrm{~nm}$ using colorimeter at $1 \mathrm{~min} 30 \mathrm{~s}$ and Abs B at $3 \mathrm{~min} 30 \mathrm{~s}$. For Sample: $2.8 \mathrm{ml}$ Tris $+0.1 \mathrm{ml}$ sample and $0.1 \mathrm{ml}$ Pyrogallol were added and mixed well, and the Abs were read at $420 \mathrm{~nm}$ after $1 \mathrm{~min} 30 \mathrm{~s}$ (Abs A) and after $3 \mathrm{~min} 30 \mathrm{~s}$ (Abs B) [16].

SOD levels (in Units) were calculated using the formula: Abs (A-B)/Abs $\mathrm{A} \times 50$

\section{Estimation of MDA}

Reagents used were trichloroacetic acid (TCA) - 40\% (40 g in $100 \mathrm{ml}$ ), thiobarbituric acid (TBA) - 0.67\% (0.67 g in $100 \mathrm{ml})$. Then, $0.5 \mathrm{ml}$ sample $+0.5 \mathrm{ml} \mathrm{TCA}+2 \mathrm{ml}$ TBA were added very slowly. The test tubes were kept in a boiling water bath at $90-100^{\circ} \mathrm{C}$ for $10 \mathrm{~min}$. After $10 \mathrm{~min}$, the tubes were brought back to the room temperature. Samples were centrifuged for $10 \mathrm{~min}$ at $3000 \mathrm{rpm}$. Separated the supernatant and readings were taken at $540 \mathrm{~nm}$ using colorimeter [16].

MDA levels (in units) were calculated using the formula: Abs at $532 \mathrm{~nm}$ $\times 105 / 1.56$

\section{Statistics}

Data from the control and two treatment groups were analyzed by ANOVA in SPSS software version 24.

\section{RESULTS}

In vitro study

Chemical testing

Fresh juice and dry powder preparations of EO were found to be positive for all the four chemical testing.

\section{DPPH FREE RADICAL ASSAY}

In DPPH assay, dry powder of EO showed 97\% inhibition of free radical scavenging activity compared to its fresh juice preparation and standard (ascorbic acid), which were about 57\% and 76\%, respectively.

\section{In vivo study}

In this study, after the $1^{\text {st }}$ day of stress induction, rats showed changes in the mean values of body weight, food intake pattern, behavior changes, and SOD and MDA levels in both the treatment group of EO ( $250 \mathrm{mg} / \mathrm{kg}$ and $500 \mathrm{mg} / \mathrm{kg}$ ) in comparison to the control group (without treatment) and their baseline values. More statistically significant values were seen in the E0 $500 \mathrm{mg} / \mathrm{kg}$ treated group for body weight $\left({ }^{*} \mathrm{p}=0.01\right)$, behavior changes $\left({ }^{*} \mathrm{p}<0.01\right)$, and SOD $\left({ }^{*} \mathrm{p}=0.01\right)$ (Figs. $\left.1-3\right)$.

Similarly, after 7 days of repeated stress induction, rats showed, change in the mean values of body weight, food intake, behavior changes, and

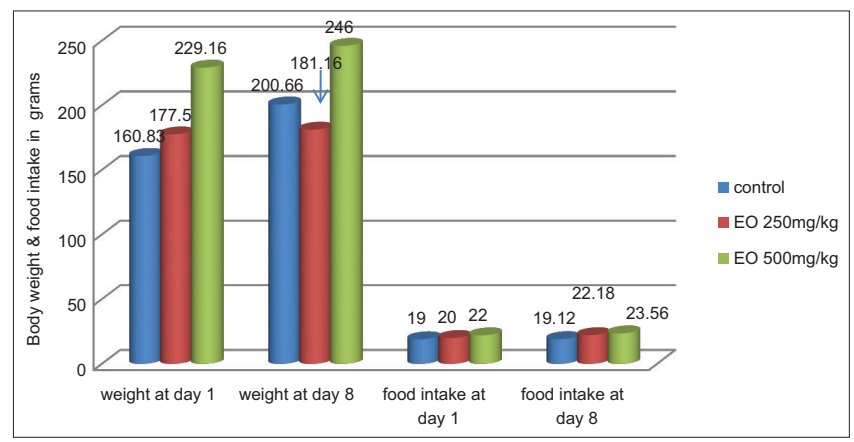

Fig. 1: Mean \pm standard deviation values of body weight $\left({ }^{*} \mathbf{p}<0.05\right)$ and food intake pattern after stress induction 


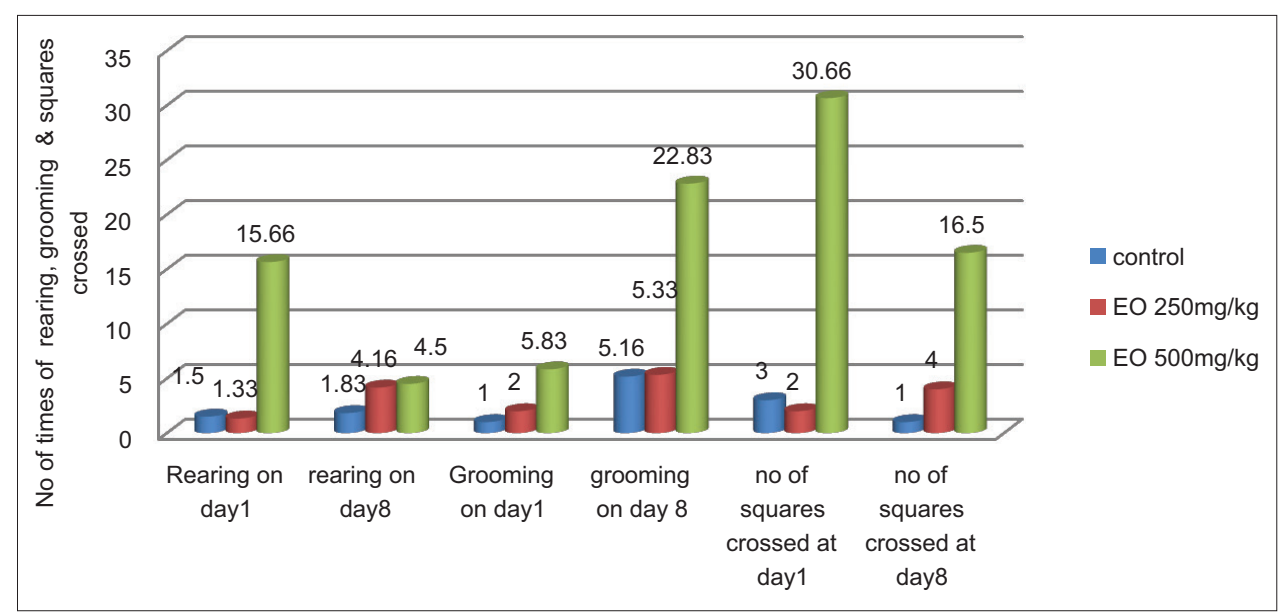

Fig. 2: Mean \pm SD values of behavior parameters in open field test after stress induction $\left({ }^{*} p<0.01\right)$

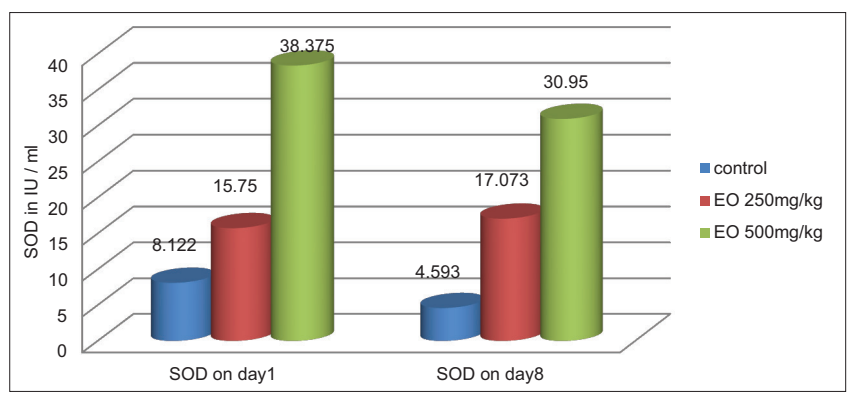

Fig. 3: Mean \pm SD values of superoxide dismutase in $\mathrm{IU} / \mathrm{ml}$ after stress induction $\left({ }^{*} \mathrm{p}<0.05\right)$

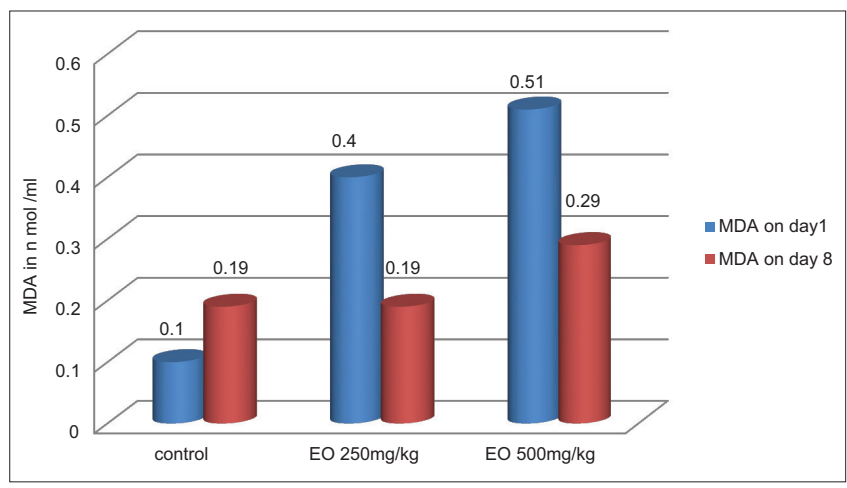

Fig. 4: Mean \pm SD values of malondialdehyde levels after stress induction $(* p<0.05)$

SOD and MDA levels in both the treatment groups. However, statistically significant changes were seen in the body weight $\left({ }^{*} p<0.01\right)$, SOD $\left({ }^{*} \mathrm{p}=0.01\right)$, and MDA $\left({ }^{*} \mathrm{p}=0.04\right)$ levels only in the treatment group of EO $500 \mathrm{mg} / \mathrm{kg}$ (Figs. 1, 3 and 4).

Mean values of baseline parameters were weight $-160.833 \pm 11.58 \mathrm{~g}$, food intake $-19.260 \pm 10.00$ g, rearing $-3.500 \pm 4.0866$, grooming $-13.500 \pm 7.7136$, squares crossed-5.333 \pm 11.2190 , SOD-11.007 $\pm 10.45 \mathrm{IU} / \mathrm{ml}$, and MDA-1.0596 $\pm 1.1341 \mathrm{IU} / \mathrm{ml}$.

\section{DISCUSSION}

\section{In vitro study}

In this study, both the dry powder and the fresh juice of EO tested positive for flavonoids and phenolic compounds (Table 1). In terms of chemical testing, these results were similar to the studies which showed the presence of flavonoids and phenolic compounds in the aqueous methanolic fruit extract of EO [17]. In DPPH assay, dry powder of EO showed $97 \%$ inhibition of free radical scavenging activity compared to its fresh juice preparation, which was about $57 \%$ (Table 2). In the previous DPPH assay, studies of EO showed that the maximum antioxidant activity was found to be in the methanolic extract $[6,17]$.

\section{In vivo study}

Stress has identified to modify body weight and food intake in animal models. Especially the restraint stress model effectively depicted the physical and psychological stress and used as an animal model of depression [1]. Many studies have shown that restraint stress suppresses body weight gain and food intake in rodents [18]. In the present study, mean values of body weight and food intake were increased in both the treatment groups after the $1^{\text {st }}$ and the 7 days of repeated stress induction compared to the control group (without treatment) in which there was a reduction in the mean values of body weight and food intake pattern after repeated stress induction. This showed that there was reduction in the body weight and food intake pattern in restraint stress animals whereas, in the treatment groups (EO $250 \mathrm{mg} / \mathrm{kg}$ and $500 \mathrm{mg} / \mathrm{kg}$ ) the animals had overcome the stress induction and they have followed the normal physiological increase in the body weight and food intake pattern (Fig. 1).

In case of behavior changes and blood levels of SOD and MDA, there were reduction in the mean value of rearing, grooming, number of square crossed and decreased level of SOD and increased level of MDA values in the control group (without treatment) compared to its baseline values indicating a state of psychological depression immediately after the $1^{\text {st }}$ day and the 7 days of repeated stress induction. The two groups treated with the EO $(250 \mathrm{mg} / \mathrm{kg}$ and $500 \mathrm{mg} / \mathrm{kg})$ showed a better increase in mean values of rearing, grooming, number of squares crossed in parallel to increase in SOD, and decreased in MDA values after the $1^{\text {st }}$ day and the 7 days of repeated stress induction (Figs. 2-4) This ensures that the treatment with EO had overcome the changes of stress induction, including antioxidant levels, which were comparable to the results of a few previous studies wherein the antioxidant property of EO was due to the presence of polyphenols in the fruit $[19,20]$.

The results of the study clearly revealed the antioxidant effect of EO in overcoming stress induction. Improved changes in the body weight, food intake, and behavior might depict the antidepressant and antianxiety property of $E$. officinalis. These results were proven by the previous studies, by forced swim test, tail suspension test, elevated plus maze, and open field method with standard drugs. Apart from increased antioxidant levels, no other clear mechanism could be elicited behind the improved changes in food intake and body weight after repeated stress induction. Therefore, the proposed pharmacological mechanism behind these effects could be the involvement of monoaminergic neurotransmitters $[19,21,22]$. 
Table 1: Results of chemical testing

\begin{tabular}{|c|c|c|c|c|}
\hline \multirow[t]{2}{*}{ Preparations } & \multicolumn{2}{|l|}{ Phenolic compound } & \multicolumn{2}{|l|}{ Flavonoids } \\
\hline & Ferric chloride test & Lead acetate test & Aqueous sodium hydroxide test & Sulphuric acid test \\
\hline Fresh juice of EO & + & + & + & + \\
\hline Dry powder of EO & + & + & + & + \\
\hline
\end{tabular}

EO: Emblica officinalis; +: Presence/Test positive

Table 2: Percentage inhibition of free radical scavenging activity in 2,2-diphenyl-1-picryl-hydrazyl-hydrate assay

\begin{tabular}{lll}
\hline Samples & Absorbance & Percentage inhibition \\
\hline Ascorbic acid $(50 \mathrm{ng} / \mathrm{ml})$ & 0.206 & 76 \\
EO (dry powder $1 \% \mathrm{w} / \mathrm{v})$ & 0.024 & 97 \\
EO (fresh juice $1 \% \mathrm{v} / \mathrm{v})$ & 0.364 & 57 \\
\hline
\end{tabular}

EO: Emblica officinalis

The previous studies also confirmed that the present of phytochemicals in the EO such as tannic acid, gallic acid, flavonoids, and ascorbic acid might contribute to increase the levels of monoaminergic neurotransmitters and neurotropic action in the hypothalamus $[21,22]$. The monoamine receptors such as 5-hydroxytryptamine (5HT1A) and 5HT2C have their involvement in the appetite and satiety center in the brain. Hence, further studies could look into the involvement of 5HT, behind the effects of EO.

\section{CONCLUSION}

In vitro study, both the chemical testings' and DPPH assay showed maximum antioxidant activity in the dry powder preparation of EO compared to its fresh juice. In vivo study has brought out the reversal of restraint stress-induced behavioral changes and reduced antioxidant levels in a rat model. Further studies might focus to elucidate the various possible molecular mechanisms of action of EO in overcoming stress induction.

\section{AUTHORS' CONTRIBUTIONS}

Umamaheswari Anbarasu design the study executed the assays and participated in the writing of the entire manuscript. Bhuvaneswari $\mathrm{K}$ initiated the hypothesis and designed the study. Muthuraman PL participated in the animal handling and performance of in vitro and in vivo assays.

\section{CONFLICT OF INTEREST}

The authors report no conflicts of interest regarding this manuscript.

\section{REFERENCES}

1. Bekris S, Antoniou K, Daskas S, Papadopoulou-Daifoti Z. Behavioural and neurochemical effects induced by chronic mild stress applied to two different rat strains. Behav Brain Res 2005;161:45-59.

2. Badhani S, Kainth A, Kabra A, Parashar B. Evaluation of antioxidant activity of Benincasa hispida fruit extracts. Am J Pharm Tech Res 2013;3:336-45.

3. Abdullah N, Kamarudin W, Samicho Z, Zulkifli KS, Saidatul SW. Study on antioxidant capacity and phenolic content of various parts of wax gourd (Benincasa hispida). World Appl Sci J 2012;19:1051-6.

4. Bharathi S, Kumaran S, Suresh G, Ramesh B, Sundari MN. Phytosynthesis of silver nanoparticles using Hygrophila auriculata leaf extract and assessment of their antibacterial and antioxidant properties.
Int J Appl Pharm 2019;10:112-8.

5. Nadheesha M, Bamunuarachchi A, Edirisinghe EM, Weerasinghe WM. Studies on antioxidant activity of Indian gooseberry fruit and seed. J Sci Univ 2007;3:83-92.

6. Luqman S, Kumar R. Correlation between scavenging property and antioxidant activity in the extracts of Emblica officinalis Gaertn.,syn. Phyllanthus emblica L. Fruit. Ann Phytomed 2012;1:54-61.

7. Bhatnagar S, Vining C, Iyer V, Kinni V. Changes in hypothalamicpituitary-adrenal function, body temperature, body weight and food intake with repeated social stress exposure in rats. J Neuroendocrinol 2006;18:13-24.

8. Elangovan M, Dhanarajan M, Rajalakshmi A, Jayachitra A, Mathi P, Bhogireddy $\mathrm{N}$, et al. Analysis of phytochemicals, antibacterial and antioxidant activities of Moringa oleifera Lam. Leaf extract an in vitro study. Int J Drug Dev Res 2014;6:173-80.

9. Patel RM, Patel NJ. In vitro antioxidant activity of coumarin compounds by DPPH, superoxide and nitric oxide free radical scavenging methods. J Adv Pharm Educ Res 2011;1:52-68.

10. Garcia EJ, Oldoni TL, Alencar SM, Reis A, Loguercio AD, Grande RH, et al. Antioxidant activity by DPPH assay of potential solutions to be applied on bleached teeth. Braz Dent J 2012;23:22-7.

11. Melanathuru V, Rengarajan S, Thangavel N. Comparative study of antioxidant and anticancer activity of Alpinia calcarata and Alpinia galanga. Int J Pharm Pharm Sci 2017;9:186-93.

12. Balakrishnan BB, Krishnasamy K. Evaluation of free radical screening and antioxidant potential of Moringa concanensis Nimmo a medicinal plant used in Indian traditional medication system. Int J Pharm Pharm Sci 2018;10:91-7.

13. Govind P, Pandey SP. Phytochemical and toxicity study of Emblica officinalis. Int Res J Pharm 2011;2:270-2.

14. Tasanarong A, Kongkham S, Itharat A. Antioxidant effect of Phyllanthus emblica extract prevents contrast-induced acute kidney injury. BMC Complement Altern Med 2014;14:138.

15. Bolivar VJ, Caldarone BJ, Reilly AA, Flaherty L. Habituation of activity in an open field: A survey of inbred strains and F1 hybrids. Behav Genet 2000;30:285-93.

16. Todorova I, Simeonova G, Kyuchukova D, Dinev D, Gadjeva V. Reference values of oxidative stress parameters (MDA, SOD, CAT) in dogs and cats. Comp Clin Pathol 2005;13:190-4.

17. Sadoni H, Sharma P, Waheed SM, Singh S. Phytochemical analyses and evaluation of antioxidant, antibacterial and toxic properties of Emblica officinalis and terminalia bellirica fruit extracts. Asian J Pharm Clin Res 2016;9:96-102.

18. Jeong JY, Lee DH, Kang SS. Effects of chronic restraint stress on body weight, food intake, and hypothalamic gene expressions in mice. Endocrinol Metab (Seoul) 2013;28:288-96.

19. Kumar CP. Effect of Emblica officinalis on stress induced biochemical and psychological changes in mice. Glob J Med Res 2014;13:25-8.

20. Pal R, Gulati K, Chakraborti A, Banerjee B, Ray A. Role of free radicals in stress-induced neurobehavioural changes in rats. Indian J Exp Biol 2006;4:816-20.

21. Dhingra D, Joshi P, Gupta A, Chhillar R. Possible involvement of monoaminergic neurotransmission in antidepressant-like activity of Emblica officinalis fruits in mice. CNS Neurosci Ther 2012;18:419-25.

22. Pemminati S, Gopalakrishna HN, Shenoy AK, Sahu SS, Mishra S, Meti V, et al. Antidepressant activity of aqueous extract of fruits of Emblica officinalis in mice. Int J Appl Biol Pharm Technol 2010;1:448-54. 